\title{
Inclusão laboral de pessoas com deficiências no Tribunal de Justiça de Pernambuco
}

\section{(TJPE)}

\author{
Labor inclusion of people with disabilities in the Court of Justice of Pernambuco (TJPE) \\ Inclusión laboral de personas con discapacidad en el Tribunal de Justicia de Pernambuco (TJPE)
}

Recebido: 18/07/2021 | Revisado: 22/07/2021 | Aceito: 23/07/2021 | Publicado: 31/07/2021

\author{
Luciana Muniz Bezerra Schafhauzer \\ ORCID: https://orcid.org/0000-0001-8212-9163 \\ Universidade de Pernambuco, Brasil \\ E-mail: luciana.mbezerra@upe.br \\ Cleomacio Miguel da Silva \\ ORCID: https://orcid.org/0000-0002-0217-1087 \\ Universidade de Pernambuco, Brasil \\ E-mail:cleomacio@hotmail.com
}

\begin{abstract}
Resumo
O Tribunal de Justiça de Pernambuco (TJPE), desde 2001, mantem em seus concursos públicos cotas para absorver e valorizar a força de trabalho de pessoas com deficiência, possuindo hoje, em seu quadro funcional, 179 servidores com algum tipo de deficiência, que trabalham em diferentes atividades e setores da organização, em todo o Estado de Pernambuco. Para uma atuação profissional integral, o acesso às ferramentas tecnológicas deveria atender a todos os servidores indistintamente. A falta de adaptação dos serviços de TIC aos servidores com deficiência do TJPE, pode levar a um desestímulo à sua utilização, impedindo que o indivíduo exerça toda sua potencialidade laboral por não aproveitar totalmente as ferramentas tecnológicas disponíveis. Dentro desse contexto, o objetivo do presente trabalho foi realizar um levantamento bibliográfico sobre a inclusão laboral e o uso de ferramentas tecnológicas pelos servidores com deficiência do TJPE, com a finalidade de buscar soluções para uma gestão de serviços de TIC inclusiva e acessível. A pesquisa documental utilizou as diretrizes da metodologia Prisma, buscando entendimento legal histórico da inclusão laboral, as práticas de TIC para acessibilidade e as experiências vivenciadas no TJPE. Esse levantamento preliminar visa, no futuro, a elaboração de uma Cartilha de Boas Práticas de Gestão de Serviços de TIC no TJPE, para pessoas com deficiência visual. Os resultados obtidos mostraram que, embora exista um movimento para adaptação das ferramentas tecnológicas aos servidores com deficiência visual no TJPE, ainda há a necessidade de uma política de gestão mais efetiva e eficaz para o completo aproveitamento laboral desses servidores.
\end{abstract}

Palavras-chave: Deficiente visual; Inclusão laboral; Tecnologia inclusiva; Tecnologia assistiva.

\begin{abstract}
The Court of Justice of Pernambuco (TJPE), since 2001, has maintained quotas in its public examinations to absorb and enhance the workforce of people with disabilities, and currently has 179 civil servants with some type of disability in its workforce. in different activities and sectors of the organization, throughout the State of Pernambuco. For a full professional performance, access to technological tools should serve all servers without distinction. The lack of adaptation of ICT services to TJPE servers with disabilities can lead to discouragement of its use, preventing the individual from exercising all their work potential by not fully taking advantage of the available technological tools. Within this context, the objective of the present work was to carry out a bibliographical survey on labor inclusion and the use of technological tools by the TJPE servers with disabilities, in order to seek solutions for an inclusive and accessible ICT service management. The documental research used the guidelines of the Prisma methodology, seeking historical legal understanding of labor inclusion, ICT practices for accessibility and experiences lived in the TJPE. This preliminary survey aims, in the future, to prepare a Booklet of Good Practices for the Management of ICT Services at the TJPE, for people with visual impairments. The results obtained showed that, although there is a movement to adapt technological tools to visually impaired servers at TJPE, there is still a need for a more effective and efficient management policy for the full labor utilization of these servers.
\end{abstract}

Keywords: Visually impaired; Labor inclusion; Inclusive technology; Assistive technology.

\section{Resumen}

El Tribunal de Justicia de Pernambuco (TJPE), desde 2001, mantiene cuotas en sus exámenes públicos para absorber y potenciar la plantilla de personas con discapacidad, y actualmente cuenta con 179 funcionarios con algún tipo de discapacidad en su plantilla. sectores de la organización, en todo el estado de Pernambuco. Para un pleno desempeño profesional, el acceso a las herramientas tecnológicas debe servir a todos los servidores sin distinción. La falta de adecuación de los servicios TIC a los servidores TJPE con discapacidad puede llevar a desalentar su uso, impidiendo 
que el individuo ejerza todo su potencial laboral al no aprovechar al máximo las herramientas tecnológicas disponibles. En este contexto, el objetivo del presente trabajo fue realizar una encuesta bibliográfica sobre la inclusión laboral y el uso de herramientas tecnológicas por parte de los servidores de TJPE con discapacidad, con el fin de buscar soluciones para una gestión de servicios TIC inclusiva y accesible. La investigación documental utilizó los lineamientos de la metodología Prisma, buscando la comprensión jurídica histórica de la inclusión laboral, las prácticas de las TIC para la accesibilidad y las experiencias vividas en el TJPE. Esta encuesta preliminar tiene como objetivo, en el futuro, la elaboración de un Folleto de Buenas Prácticas para la Gestión de los Servicios TIC en el TJPE, para personas con discapacidad visual. Los resultados obtenidos mostraron que, si bien existe un movimiento para adaptar las herramientas tecnológicas a los servidores con discapacidad visual en TJPE, aún existe la necesidad de una política de gestión más efectiva y eficiente para la plena utilización laboral de estos servidores.

Palabras clave: Deficientes visuales; Inclusión laboral; Tecnología inclusiva; Tecnología de asistencia.

\section{Introdução}

A Declaração Universal dos Direitos Humanos, em 1948, já preconizava, em seu art. 23 (ONU, 1948), condições equitativas e satisfatórias de trabalho sem discriminação. Em 1993, a ONU publicou as Normas Gerais para a Equiparação de Oportunidades das Pessoas com Deficiência (ONU, 1993), reforçando a ideia da pessoa com deficiência produtiva e socialmente e economicamente ativa. Em 2012, foram idealizados os Objetivos de Desenvolvimento Sustentável (ODS), onde o ODS 8 reforça o tema de trabalho e desenvolvimento econômico inclusivo e sustentável (Brasil, 2021). No Brasil, em 2015, foi publicada a Lei Brasileira de Inclusão da Pessoa com Deficiência, trazendo um capítulo específico de Direito do Trabalho (Brasil, 2015). Cronologicamente, observa-se uma luta histórica e uma evolução legal na busca para garantir à cada pessoa com deficiência $(\mathrm{PcD})$, mais oportunidades de inserção no mercado de trabalho.

O direito ao trabalho é um dos principais caminhos para a inclusão social das pessoas com deficiência (Milena Oliveira, 2017). Atualmente, a inclusão laboral de PcD tem avançado significativamente, embora ainda, muito baseado em obrigações legais. Motivados pelo desejo de serem produtivos e pela dignidade de viverem economicamente independentes, pessoas com deficiência têm vencido as barreiras da educação, que ainda precisa se firmar como inclusiva, e chegam ao mercado de trabalho precisando se impor diante das suas limitações. A absorção dessa mão de obra ainda é recheada de preconceitos, principalmente pela falta de conhecimento do potencial que a pessoa com deficiência possui.

Acompanhando a mudança de perspectiva sociocultural mundial em busca de uma gestão laboral inclusiva, o Poder Judiciário brasileiro vem incentivando e normatizando a absorção dessa força de trabalho em suas unidades organizacionais. Dentro desse contexto, o Tribunal de Justiça de Pernambuco (TJPE) mantém em seus concursos público, desde 2001, percentual de vagas destinadas às pessoas com deficiência, respeitando o quantitativo definido pela legislação nacional, possuindo hoje em seu quadro funcional 179 servidores concursados que ocupam diferentes categorias funcionais, trabalhando em diferentes setores e distribuídos em todo o estado.

Principalmente regidas por normativas do Conselho Nacional de Justiça (CNJ), que se encontram alinhadas com a legislação nacional, as conquistas dos servidores com deficiência do TJPE vêm evoluindo com o processo de inclusão dentro do Poder Judiciário. Foram identificadas resoluções, diretrizes e ações, que adequam e trabalham a acessibilidade e inclusão na organização, e vem se atualizando e se adequando à medida que as realidades vão sendo conhecidas. A Secretaria de Gestão de Pessoas (SGP) e a Comissão de Acessibilidade de Inclusão (CACIN) são as unidades responsáveis pela promoção da adaptação laboral dos servidores com deficiência dentro do órgão.

Para adaptação de um ambiente de trabalho realmente inclusivo, como coloca Verçosa (2017), é necessário conjugar tanto fatores relacionais como estruturais e pensar de forma ampla a inclusão física, psicológica e social para a garantia de um ambiente de trabalho que garanta qualidade de vida a todos as pessoas indistintamente.

Em decorrência do grande avanço científico e tecnológico, as organizações dependem grandemente dos serviços de Tecnologia da Informação e Comunicação (TIC). Dentro do contexto da inclusão laboral de pessoas com deficiência, a TIC se 
constitui uma excelente ferramenta de suporte, principalmente, para deficientes visuais. O primeiro passo para propor mudanças que levem não somente à utilização de novas tecnologias, mas a um pensamento de cultura de inclusão de pessoas com deficiência, é levar em consideração as suas experiências e sugestões na tomada de decisão de qualquer processo dentro de suas atividades laborais.

E embora já exista uma preocupação em garantir tecnologia assistiva para uso dos servidores com deficiência em seus postos de trabalho, através de levantamento de necessidades executado pela Unidade de Acompanhamento Funcional (UAF) da SGP, observa-se uma lacuna na falta de um processo eficiente e eficaz para a aquisição desses equipamentos. Também, embora se perceba a preocupação com a acessibilidade, observada no novo site do TJPE, os sistemas informatizados que atendem as áreas administrativas e judiciais do órgão carecem de uma revisão para verificação da acessibilidade.

Existe a necessidade de se desenvolver uma cultura organizacional no TJPE que proporcione uma inclusão efetiva e que envolva equipe multidisciplinar para que os diferentes olhares pensem e executem ações inclusivas, visando beneficiar tanto os servidores do órgão, como o jurisdicionado. Reconhece-se que a mudança cultural e a quebra de velhos paradigmas demandam tempo e exige desenvolvimento de novas habilidades para todos os servidores. Sendo assim, e dentro desse contexto, a presente pesquisa teve como objetivo fazer um levantamento bibliográfico sobre a inclusão laboral e o uso de ferramentas tecnológicas pelos servidores com deficiência do TJPE, com a finalidade de buscar soluções para uma gestão de serviços de TIC inclusiva e acessível.

\section{Metodologia}

O levantamento de documentos para realização desse estudo partiu dos seguintes questionamentos: (1) quais os dispositivos que regem a inclusão laboral de pessoas com deficiências no TJPE? (2) como essa prática está sendo realizada dentro da organização? e (3) o suporte de TIC tem favorecido a inclusão laboral do servidor com deficiência visual no TJPE? Para tanto, foi utilizada a metodologia PRISMA para sistematização da pesquisa.

Composto por um checklist de 27 itens e 1 fluxograma, as diretrizes da metodologia PRISMA se propõem a auxiliar na escolha dos documentos mais relevantes para a pesquisa (Lima et al., 2017). Segundo Galvão e Ricarte (2020), uma revisão da literatura sistemática é uma modalidade de pesquisa que segue tópicos específicos, buscando dar uma lógica ao corpo documental.

Os questionamentos norteadores da pesquisa seguiram o acrônimo PICO que, como explica Galvão e Ricarte (2020), delineiam os levantamentos nos componentes população $(\mathrm{P})$, intervenção $(\mathrm{I})$, controle $(\mathrm{C})$ e outcome $(\mathrm{O}$, traduzido como resultado). Ressalta-se que no presente estudo não haverá comparação (C) entre intervenções.

Foram realizadas buscas de documentos, com acesso totalmente aberto, nas bases SCOPUS, SciELO, Web of Science (WoS), Banco de teses IBICT e Google Scholar, para publicações no período de 2005 a 2021, utilizando descritores DECs e MeSH: Pessoas com Deficiência (D006233); Equipamentos de Autoajuda (tecnologia assistiva) (D012656); Tecnologia da Informação (D000073256); Readaptação ao Emprego (Emprego com Apoio Especial) (D016832). Para aumento da sensibilidade da pesquisa foi utilizado o termo "inclusão laboral" como substituição do descritor "Readaptação ao Emprego", e feito cruzamento dos descritores nos idiomas português e inglês com os operadores booleanos AND/OR (Quadro 1).

Pela especificidade da pesquisa, também foram consultadas literaturas não publicadas disponíveis no âmbito do TJPE, consultas a documentos disponibilizados em websites, realizada busca manual através da verificação da lista de "Referências bibliográficas" de documentos incluídos em revisão prévia e buscas de normativos legais nos sites do TJPE, CNJ e Presidência da República. 
O critério de inclusão obedeceu às seguintes etapas: leitura dos títulos e exclusão dos que não se adequaram ao tema da pesquisa, leitura dos resumos e exclusão dos que não tinham aderência ao assunto pretendido e leitura na íntegra para seleção dos artigos que melhor se adequassem ao foco da pesquisa (Figura 1) (Prisma, 2021).

Foram pesquisados 21 arquivos de trabalhos acadêmicos coletados nas bases de dados, através de busca manual e em pesquisas anteriores, onde apenas 1 deles não teve publicação, tendo sido elegido para compor essa pesquisa por se tratar de tema similar. Verificando as datas de publicação desses arquivos, observou-se que a partir do ano de 2019, houve um incremento de estudos anuais publicados relativos às pessoas com deficiência, trabalho e tecnologias, demonstrando que o tema tem sido uma preocupação atual (Figura 2).

De maneira específica, quanto à inclusão laboral em órgãos públicos, pelo objetivo da pesquisa, as normas e as legislações foram os grandes alicerces desse estudo. Dentro dos arquivos incluídos na revisão, apenas 3 deles abordam a realidade das instituições públicas, demonstrando a escassez de estudos para essa realidade, sendo um campo vasto de pesquisa a ser investigado. Decorrente dessa escassez, o descritor Poder Público (DDCS036440) não foi utilizado.

De maneira geral, os arquivos incluídos na revisão convergem quanto à necessidade de mais ações afirmativas para a inclusão laboral da pessoa com deficiência, quanto à necessidade de sensibilização nos ambientes de trabalho para quebra de paradigmas e quanto à escassez de pesquisas na área.

A pesquisa efetuada seguindo as diretrizes da metodologia PRISMA proporcionou maior organização para o levantamento de abordagens sobre o tema, bem como permitiu constatar que se trata de um campo de estudo que ainda precisa ser mais explorado.

Quadro 1. Estratégias de busca sistemática para revisão da literatura.

\begin{tabular}{|c|c|c|}
\hline $\begin{array}{c}\text { Base de } \\
\text { Dados }\end{array}$ & Cruzamento de descritores & Qtd \\
\hline $\begin{array}{l}\text { Web of } \\
\text { Science }\end{array}$ & $\begin{aligned} \text { ts } & =(\text { People with Disabilities AND Assistive Technology AND Labor Inclusion) } \\
\text { ts } & =(\text { Pessoa com deficiência AND Tecnologia Assistiva AND Inclusão Laboral) } \\
\text { ts } & =(\text { People with Disabilities AND Labor Inclusion AND Information Technology) } \\
\text { ts } & =(\text { Pessoa com Deficiência AND Inclusão Laboral and Tecnologia da Informação) }\end{aligned}$ & $\begin{array}{c}5 \\
0 \\
10 \\
0\end{array}$ \\
\hline Scielo & $\begin{array}{l}\text { (People with Disabilities) AND (Assistive Technology) AND (Labor Inclusion) } \\
\text { (Pessoa com Deficiência) AND (Tecnologia Assistiva) AND (Inclusão Laboral) } \\
\text { (People with Disabilities) AND (Labor Inclusion) AND (Information Technology) } \\
\text { (Pessoa com Deficiência) AND (Inclusão Laboral) AND (Tecnologia da Informação) }\end{array}$ & $\begin{array}{l}0 \\
0 \\
2 \\
0\end{array}$ \\
\hline Scopus & $\begin{array}{l}\text { TITLE-ABS-KEY ( people AND with AND disabilities ) AND ( assistive AND } \\
\text { technology ) AND ( labor AND inclusion ) } \\
\text { TITLE-ABS-KEY ( people AND with AND disabilities ) AND ( labor AND } \\
\text { inclusion ) AND ( information AND technology ) }\end{array}$ & 27 \\
\hline Ibict & $\begin{array}{c}\text { Busca: (Todos os campos:pessoa com deficiência E Todos os campos:TECNOLOGIA } \\
\text { ASSISTIVA E Todos os campos:INCLUSÃO LABORAL) } \\
\text { Busca: (Todos os campos:People with Disabilities E Todos os campos:Labor Inclusion E } \\
\text { Todos os campos:assistive Technology) } \\
\text { Busca: (Todos os campos:People with Disabilities E Todos os campos:Labor Inclusion E } \\
\text { Todos os campos:Information Technology) } \\
\text { Busca: (Todos os campos:pessoa com deficiência E Todos os campos:TECNOLOGIA da } \\
\text { informação E Todos os campos:INCLUSÃO LABORAL) }\end{array}$ & 2 \\
\hline $\begin{array}{l}\text { Google } \\
\text { Scholar }\end{array}$ & $\begin{array}{l}\text { "Pessoa com Deficiência" AND "Tecnologia da informação" AND "Inclusão Laboral" } \\
\text { "Pessoa com Deficiência" AND "Tecnologia assistiva" AND "Inclusão Laboral" }\end{array}$ & $\begin{array}{l}30 \\
85\end{array}$ \\
\hline
\end{tabular}

Fonte: Autores. 
Research, Society and Development, v. 10, n. 9, e47810918371, 2021

(CC BY 4.0) | ISSN 2525-3409 | DOI: http://dx.doi.org/10.33448/rsd-v10i9.18371

Figura 1. Diagrama de fluxo da metodologia PRISMA.

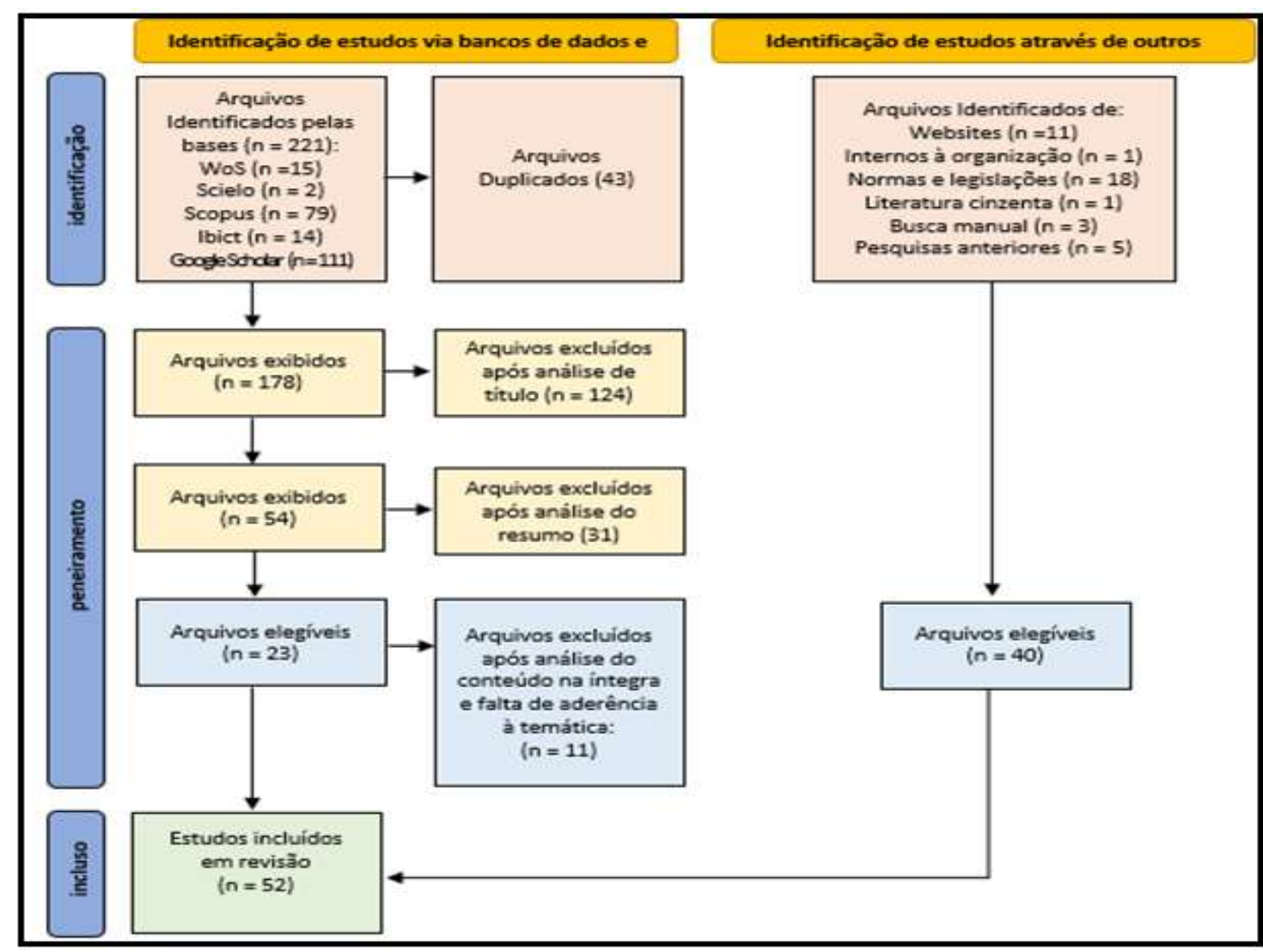

Fonte: Autores.

Figura 2. Número de publicações selecionadas por ano.

\section{Publicaçōes selecionadas por ano}

6

5

4

$2 \quad 2$

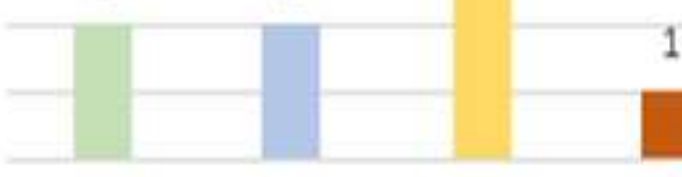

Fonte: Autores. 


\section{Resultados e Discussão}

\subsection{Inclusão laboral na legislação brasileira}

Foi a partir da Constituição Federal de 1988 (Brasil, 1988) que o poder público normatizou a necessidade de inclusão das pessoas com deficiência, abraçando em seu texto a igualdade de direitos e a dignidade da pessoa humana, trazendo o ordenamento jurídico para a inclusão social e laboral, não permitindo uma cidadania separada para a PcD (Maior, 2017). A Carta Magna Brasileira, em seu art. 37, que apresenta os princípios da legalidade, impessoalidade, moralidade, publicidade e eficiência, vigora no inciso VIII, que "a lei reservará percentual dos cargos e empregos públicos para as pessoas portadoras de deficiência e definirá critérios de sua admissão”.

O empenho do Poder Público na integração laboral da pessoa com deficiência teve representatividade na Lei $n^{\circ}$ 7.853/1989 (Brasil, 1989), quando na alínea “d”, do inciso III do art. $2^{\circ}$ preconiza:

A adoção de legislação específica que discipline a reserva de mercado de trabalho, em favor das pessoas portadoras de deficiência, nas entidades da Administração Pública e do setor privado, e que regulamente a organização de oficinas e congêneres integradas ao mercado de trabalho, e a situação, nelas, das pessoas portadoras de deficiência.

Instituindo o Regime Jurídico dos Servidores Públicos, a Lei 8.112/1990 (Brasil, 1990), no inciso $2^{\circ}$ do art. 5, assegurou o direito das pessoas com deficiência de se inscreverem em concurso público, reservando até $20 \%$ das vagas oferecidas para essa população. Essa mesma lei trata servidores com ou sem deficiência de maneira igualitária quanto à remuneração, regras de posse, exercício da profissão e estágio probatório, estabilidade, dentre outros direitos e deveres. Prevendo uma possível necessidade de horário diferenciado por motivo de saúde, em 1997, a Lei n 9.527 (Brasil, 1997), incluiu o inciso $3^{\circ}$ do art. 98 nessa prerrogativa.

Em 1999, se colocando como uma ação afirmativa para inclusão da pessoa com deficiência no mercado de trabalho (Verçosa, 2017), o Decreto no 3.298/1999 (Brasil, 1999), que regulamentou a Lei no 7.853/1989 (Brasil, 1989), em seu art. 36, alinhou o entendimento do percentual destinado a PcD com a Lei de Cotas (Brasil, 1991), determinando o percentual:

I - até duzentos empregados, dois por cento;

II - de duzentos e um a quinhentos empregados, três por cento;

III - de quinhentos e um a mil empregados, quatro por cento; ou

IV - mais de mil empregados, cinco por cento.

A preocupação com a promoção da acessibilidade, que propicia a adaptação do ambiente para receber qualquer pessoa indistintamente, veio na Lei $n^{0} 10.098 / 2000$ (Brasil, 2000), a qual apresentou na legislação as primeiras definições das barreiras que impedem a participação social da pessoa com deficiência alertando para obstáculos, atitudes e comportamentos limitantes. Em 2004, visando a garantia do acesso à informação e à comunicação para todos, o Decreto nº 5.296 (Brasil, 2004), além de consolidar as normas anteriores, abrange a necessidade de acessibilidade nos portais e sítios eletrônicos da administração pública, tornando obrigatório à adaptação, especialmente, para as pessoas com deficiência visual.

O capítulo da inclusão laboral veio ganhando reforços durante o tempo, onde no Decreto no 6.949/2009 (Brasil, 2009) promulgou no Brasil a Convenção Internacional sobre os Direitos das Pessoas com Deficiência, e trouxe no seu art. 27, especificamente o tema "Trabalho e emprego" que aborda a oportunidade de trabalho aberto, inclusivo e acessível a PcD.

Fazendo recortes específicos nas alíneas do artigo 27, encontramos a igualdade de oportunidade para todas as pessoas, a recomendação para absorver a força de trabalho das PcD no serviço público e a garantia das adaptações ao local de trabalho, que pretende proporcionar que essas ações aconteçam de maneira sustentável, como podemos ver: 
b) Proteger os direitos das pessoas com deficiência, em condições de igualdade com as demais pessoas, às condições justas e favoráveis de trabalho, incluindo iguais oportunidades e igual remuneração por trabalho de igual valor, condições seguras e salubres de trabalho, além de reparação de injustiças e proteção contra o assédio no trabalho; [...]

g) Empregar pessoas com deficiência no setor público; [...]

i) Assegurar que adaptações razoáveis sejam feitas para pessoas com deficiência no local de trabalho;

Cabe ressaltar, que a Convenção sobre os Direitos da Pessoa com Deficiência, por sua importância, foi o primeiro “documento internacional de direitos humanos com caráter de Emenda Constitucional no Brasil”, que mudou o paradigma da compreensão da deficiência tirando o foco do aspecto intrínseco à pessoa para as barreiras sociais, institucionais e ambientais que impedem a interação da pessoa com deficiência e seu meio (Andrade \& Bublitz, 2016).

O Estatuto da Pessoa com Deficiência, Lei no 13.146/2015 (Brasil, 2015), agregou as conquistas feitas até o momento de sua publicação. Ele unificou o entendimento das normativas existentes, além de fazer alterações no Código Civil, eliminando os aspectos discriminatórios que associavam a deficiência à incapacidade, buscando a igualdade plena, havendo um efetivo avanço na legislação no sentido de propiciar a inclusão (Andrade \& Bublitz, 2016).

Reconhecendo a necessidade de ajustes na regulamentação do preenchimento de cargos no serviço público por pessoas com deficiência, o Decreto no 9.508/2018 (Brasil, 2018) reafirmou a obrigatoriedade de reserva de, no mínimo, 5\% (cinco por centro) das vagas oferecidas para provimento de cargo efetivo, fazendo observação quanto ao aproveitamento de vagas remanescente e formação de cadastro reserva para esses cargos, determinando no inciso $2^{\circ}$ do art. $8^{\circ}$ :

A desclassificação, a desistência ou qualquer outro impedimento de candidato ocupante de vaga reservada implicará a sua substituição pelo próximo candidato com deficiência classificado, desde que haja candidato com deficiência classificado.

Ainda nesse Decreto, em seu art. $9^{\circ}$, coloca que as organizações “deverão providenciar a acessibilidade no local de trabalho e a adaptação razoável, quando requerida, para o efetivo exercício laboral da pessoa com deficiência.

O Estado de Pernambuco, desde o início do processo de inclusão laboral para pessoas com deficiência no Brasil, em sua Constituição de 1989, esteve alinhado com a Carta Magna prevendo, por lei, a reserva de cargos nos concursos públicos do estado, com vistas ao "ajustamento à vida social, promovendo assistência, cadastramento, treinamento, seleção, encaminhamento, acompanhamento profissional e readaptação funcional”, como se observa em todo o inciso VI do art. 97 da Constituição do Estado de Pernambuco (Pernambuco, 1989).

\subsection{Ações do Conselho Nacional de Justiça}

Seguindo a mudança de perspectiva sociocultural diante da pessoa com deficiência, o Conselho Nacional de Justiça (CNJ), que é uma instituição pública do sistema judiciário brasileiro que tem a missão de promover a eficiência, as melhores práticas e o desenvolvimento do Poder Judiciário em benefício da sociedade (CNJ, 2021 a), no mesmo ano da promulgação da Convenção sobre os Direitos das Pessoas com Deficiência no Brasil, demonstrou sensibilidade ao processo de inclusão da pessoa com deficiência na publicação da Recomendação n. 27, de 16 de dezembro de 2009, quando propôs promover a conscientização de servidores e jurisdicionados sobre ações inclusivas para remoção de barreiras físicas, arquitetônicas, de comunicação e atitudinais e, também, em sua meta “j”, recomendar que os editais de concurso tivessem previsão de cargos para pessoas com deficiência para servidores de carreira e magistratura (CNJ, 2012).

Mantendo o alinhamento com as ações afirmativas nacionais e firmando seu compromisso com o pensamento sustentável, no ano de 2015, ano da publicação do Estatuto da Pessoa com Deficiência, o CNJ publica a Resolução nº 201/2015 (CNJ, 2015), implantando o Plano de Logística Sustentável (PLS-PJ), que preconiza em seu inciso $7^{\circ}$ do Art. $6^{\circ}$ : 
A qualidade de vida no ambiente de trabalho deve compreender a valorização, satisfação e inclusão do capital humano das instituições, em ações que estimulem o seu desenvolvimento pessoal e profissional, assim como a melhoria das condições das instalações físicas.

Para acompanhamento do PLS-PJ, o Anexo I dessa resolução apresenta, dentro do tema Qualidade de vida no ambiente de trabalho, o indicador de Ações de inclusão para servidores com deficiência, que deve ter sua quantidade mensurada pelos órgãos do Poder Judiciário, para subsidiar o seu Balanço Socioambiental que é publicado anualmente no site do CNJ. Evoluindo no tema, e considerando que a acessibilidade é um direito para garantia do pleno exercício dos outros direitos, e que a igualdade de condições devem ser para todos indistintamente, inclusive o direito ao trabalho, a Resolução $\mathrm{n}^{\circ}$ 230/2016 (CNJ, 2016) orienta a adequação das atividades do Poder Judiciário para inclusão da pessoa com deficiência, visando proibir qualquer forma de discriminação, como pode ser observado em seu art. $3^{\circ}$ :

A fim de promover a igualdade, adotar-se-ão, com urgência, medidas apropriadas para eliminar e prevenir quaisquer barreiras urbanísticas, arquitetônicas, nos transportes, nas comunicações e na informação, atitudinais ou tecnológicas, devendo-se garantir às pessoas com deficiência - servidores, serventuários extrajudiciais, terceirizados ou não quantas adaptações razoáveis ou mesmo tecnologias assistivas sejam necessárias para assegurar acessibilidade plena, coibindo qualquer forma de discriminação por motivo de deficiência.

Em sua Seção III, a referida resolução trata especificamente da inclusão de pessoa com deficiência no serviço público, determinando acolhimento e adaptação às necessidades particulares de cada colaborador, que devem ser reavaliadas anualmente, com vistas a igualdade de oportunidades e colocação competitiva no ambiente de trabalho, onde o art. 24 determina:

É garantido à pessoa com deficiência acesso a produtos, recursos, estratégias, práticas, processos, métodos e serviços de tecnologia assistiva que maximizem sua autonomia, mobilidade pessoal e qualidade de vida.

Essa mesma resolução, em seu art. 10, orienta a criação de Comissões Permanentes de Acessibilidade e Inclusão por cada Tribunal para, com um olhar multidisciplinar e com a participação de magistrados e servidores com e sem deficiência, pensar e promover a inclusão da pessoa com deficiência dentro das realidades locais.

Atualizando-se diante as novas realidades identificadas, reconhecendo que a formação e o amadurecimento de equipe multidisciplinar para desenvolver a pessoa com deficiência no local de trabalho precisa de tempo e dedicação e que, muitas vezes, é necessário condições especiais de trabalho, o CNJ publicou a Resolução no 343/2020 (CNJ, 2020b) se predispondo, junto com os tribunais, estimular ações formativas de sensibilização e inclusão buscando ampliar e fortalecer o tema dentro do Poder Judiciário.

No último Balanço Socioambiental apresentado no site do CNJ, publicado no ano de 2020, referente ao acompanhamento do ano de 2015 a 2020 (Figura 3), observar-se um aumento significativo na quantidade de ações de inclusão, demonstrando uma tendência de incentivo de acolhimento e adaptação à pessoa com deficiência nos órgãos do Poder Judiciário nacional. 
Figura 3. Ações de inclusão e ações solidárias no Poder Judiciário de 2015 a 2019.

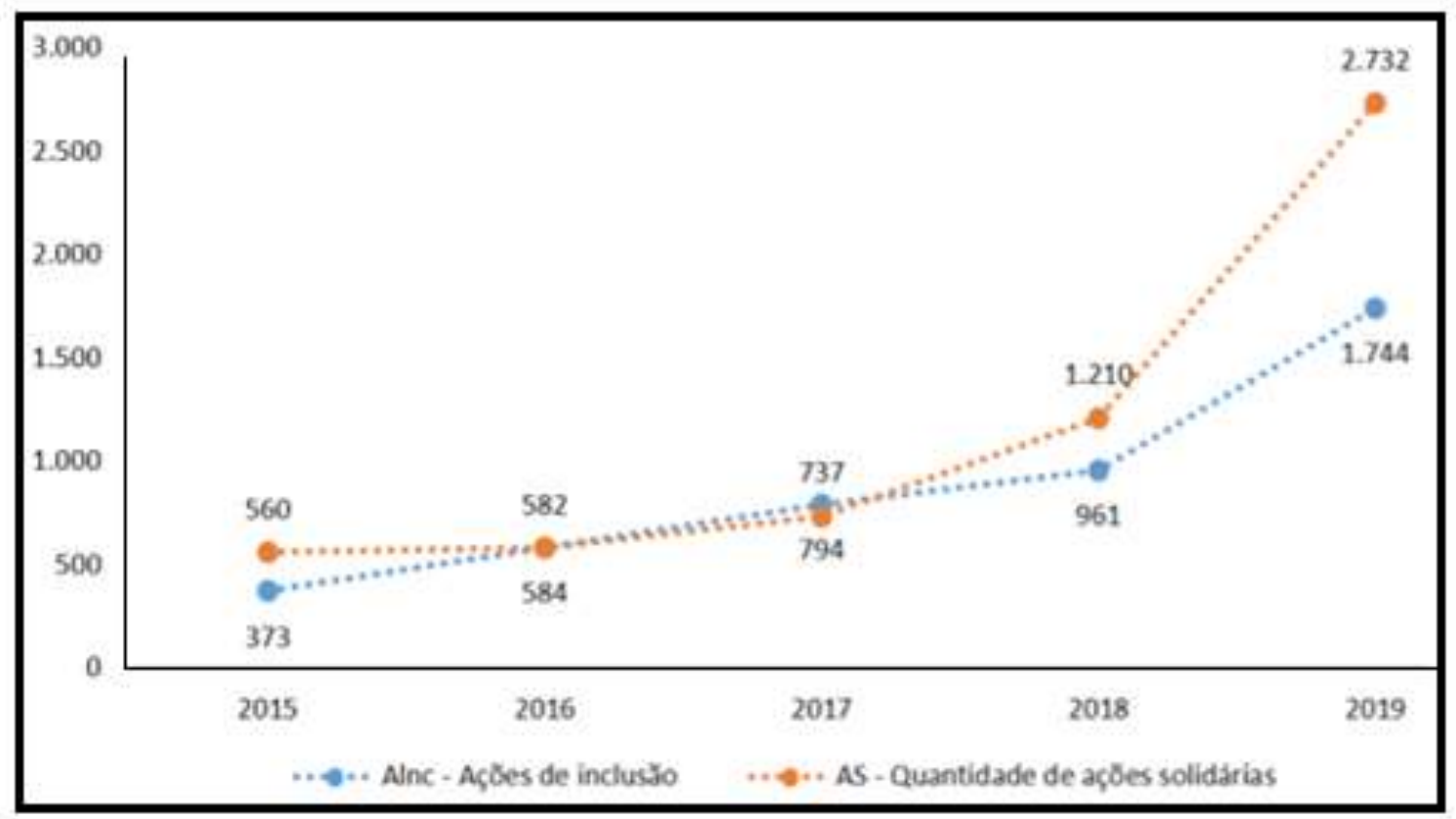

Fonte: CNJ (2020a).

Evoluindo diante à necessidade real e inadiável de implementar ações que favoreçam a inclusão tanto para servidores, como para o público externo, demonstrando aderência ao entendimento de que o processo de inclusão deve ser perene, constante e sustentável, o CNJ publicou recentemente a Resolução nº 401, de 16 de junho de 2021, regulamentando o funcionamento de unidades de acessibilidade e inclusão nos órgãos do Poder Judiciário, que ficarão responsáveis por desenvolver e acompanhar diretrizes relativas a eliminação de barreiras de quaisquer tipos. Essa mesma resolução fornece diretrizes para adaptações arquitetônicas, de mobiliários, na comunicação, nos sistemas informatizados, atitudinais ou tecnológicas (CNJ, 2021b).

\subsection{A história da inclusão laboral no TJPE}

O primeiro concurso público do Tribunal de Justiça de Pernambuco que previu cargos para pessoas com deficiência, ocorreu no ano de 2001, dois anos após o Poder Público reservar vagas para pessoas com deficiência no mercado de trabalho (Brasil, 1989), referendado pela lei maior do Estado de Pernambuco (Pernambuco, 1989), um ano após o Regime Jurídico dos Servidores Públicos assegurar vagas em concurso público (Brasil, 1990), e 13 anos após a Constituição Federal de 1988 apresentar a inclusão laboral como um processo necessário.

No edital do concurso $\mathrm{n}^{\circ}$ 01/2001 (TJPE, 2001), seu item 3 tratou especificamente das vagas destinadas às pessoas com deficiência, onde destinou 3\% (três por cento) e no mínimo de uma vaga de cada categoria funcional para PcD, obedecendo a alínea "a", do inciso VI, do art. 97 da Constituição do Estado de Pernambuco. As vagas para servidores contemplaram pessoas com escolaridade fundamental, intermediário, médio e superior. Apresentou a necessidade do exame médico oficial para validar se o grau de deficiência está de acordo com o Decreto nº 5.296 (Brasil, 2004) e garantiu igualdade de condições de participação junto aos demais candidatos, bem como atendimento especializado dentro dos critérios de viabilidade e razoabilidade. Esse Edital não explicita de maneira clara a quantidade de vagas efetivamente disponibilizadas para PcD, como também, não aborda os casos de vacância de cargos preenchidos destinados a esse público.

Em 2007, novo concurso para provimentos de cargos para servidores de carreira aberto pelo Edital nº 01/2007 (TJPE, 2007), atualizou o percentual de vagas destinadas a PcD na instituição, conforme Decreto Federal nº $3.298 / 99$ (Brasil, 1999) e 
alterações posteriores, para o percentual de 5\% (cinco por cento), garantindo atendimento especial durante o concurso, incluindo provas em Braile e com letras ampliadas. Esse edital apresentou em seu corpo, de forma clara, as características que definem a pessoa com deficiência e o quantitativo de vagas destinadas a PcD. A partir desse concurso, ficaram abertas vagas apenas para os níveis médio e superior, aumentando a necessidade de escolaridade para a participação.

O concurso para servidores de 2011 (TJPE, 2011), acresceu ao atendimento especial do concurso anterior, o atendimento à necessidade de intérprete de Libras e a possiblidade de realização de prova utilizando software leitor de tela. De maneira característica, esse concurso apresentou no item 2.1 forma peculiar de convocação de candidatos com deficiência determinando ordem de classificação específica para sua nomeação, previu cadastro reserva para esse público, mas não apresentou de forma clara a quantidade de vagas destinadas a PcD.

O último concurso para servidores feito até o presente momento, realizado em 2017, respeitou o percentual de vagas nos cargos reservadas para as pessoas com deficiência, e previu a existência de cadastro de reserva para esse público, determinando que a vacância por uma PcD deverá ser preenchida pelo próximo candidato na mesma condição, como também atualizou a possiblidade de participação para pessoas com transtorno do espectro autista (Lei $n^{\circ}$ 12.764/12) e pessoas com visão monocular (Súmula n 377 do Superior Tribunal de Justiça). O formulário de inscrição do concurso apresentou de forma clara, para a escolha do candidato, as necessidades de atendimento especial: prova em Braile, prova ampliada, prova com ledor, prova com intérprete de libras e acesso fácil (cadeirante). Esse concurso também incluiu vagas para candidatos negros demonstrando o cumprimento aos preceitos da inclusão social.

Os concursos públicos para magistrados do TJPE, ocorridos em 2010, 2012 e 2014, também contemplaram vagas destinadas a pessoas com deficiência obedecendo o percentual de 5\% das vagas ofertadas, demonstrando a inclusão em todas as esferas da organização. O panorama dos concursos que absorveram pessoas com deficiência para o corpo funcional do TJPE pode ser observado no Quadro 2.

No ano de 2019, conforme Cartilha de Inclusão e Acessibilidade do TJPE (TJPE, 2019a), a instituição somava em seu quadro funcional, 179 (cento e setenta e nove) servidores concursados portadores de deficiência, que trabalham nos mais diversos setores da organização, sendo 24 (vinte e quatro) pessoas com deficiência auditiva, 108 (cento e oito) com deficiência física/motora e 47 (quarenta e sete) com deficiência visual.

Quadro 2. Panorama dos concursos que absorveram PcD no quadro funcional do TJPE.

\begin{tabular}{|c|c|c|c|c|c|c|c|}
\hline & 2001 & 2007 & 2010 & 2011 & 2012 & 2014 & 2017 \\
\hline $\begin{array}{c}\text { Percentual } \\
\text { de vagas }\end{array}$ & $3 \%$ & $5 \%$ & $5 \%$ & $5 \%$ & $5 \%$ & $5 \%$ & $5 \%$ \\
\hline $\begin{array}{l}\text { Escolaridade } \\
\text { exigida }\end{array}$ & $\begin{array}{l}\text { fundamental } \\
\text { médio } \\
\text { superior }\end{array}$ & $\begin{array}{l}\text { médio } \\
\text { superior }\end{array}$ & superior & $\begin{array}{l}\text { médio } \\
\text { superior }\end{array}$ & superior & superior & $\begin{array}{l}\text { médio } \\
\text { superior }\end{array}$ \\
\hline Vagas total & 691 & 457 & 30 & 203 & 55 & 50 & 109 \\
\hline Vagas PcD & 26 & 26 & 2 & 7 & 3 & 3 & 2 \\
\hline $\begin{array}{l}\text { Regra de } \\
\text { vacância }\end{array}$ & $\begin{array}{c}\text { não } \\
\text { divulgada }\end{array}$ & $\begin{array}{c}\text { não } \\
\text { divulgada }\end{array}$ & $\begin{array}{l}\text { previsão } \\
\text { de } \\
\text { cadastro } \\
\text { reserva }\end{array}$ & $\begin{array}{l}\text { previsão } \\
\text { de } \\
\text { cadastro } \\
\text { reserva }\end{array}$ & $\begin{array}{l}\text { previsão } \\
\text { de } \\
\text { cadastro } \\
\text { reserva }\end{array}$ & $\begin{array}{l}\text { previsão } \\
\text { de } \\
\text { cadastro } \\
\text { reserva }\end{array}$ & $\begin{array}{l}\text { previsão } \\
\text { de } \\
\text { cadastro } \\
\text { reserva }\end{array}$ \\
\hline
\end{tabular}

Fonte: Autores. 
Ressalta-se que a quantidade de servidores PcD somados em 2019, apresentou número superior à soma de vagas levantadas nos concursos público do TJPE, pela necessidade de adequação ao percentual determinado em lei. Assim, com mais nomeações para a ampla concorrência, aumentou-se também a nomeação para pessoas com deficiência.

No pensamento de Márcia Oliveira (2017), apenas o sistema de cotas não garante uma efetiva inclusão, sendo necessário um trabalho de conscientização para o desenvolvimento de uma cultura organizacional inclusiva. Embora a previsão da reserva legal de vagas para $\mathrm{PcD}$ e a isonomia no cargo seja uma grande conquista, também é necessário que se garanta o efetivo exercício das atribuições do cargo público, dando as condições de trabalho acessíveis e adaptadas às suas necessidades individuais, não de forma paliativa, como mero arranjo administrativo, mas sim de maneira verdadeira e definitiva (Milena Oliveira, 2017).

A Secretaria de Gestão de Pessoas (SGP) do TJPE acolhe e acompanha os servidores com deficiência, desde o primeiro concurso que absorveu essa força de trabalho e, atualmente, integra em sua estrutura organizacional uma unidade específica que acompanha os servidores com deficiência em sua jornada laboral. A Unidade de Acompanhamento Funcional (UAF), da Diretoria de Desenvolvimento Humano da SGP, observando a legislação pertinente, desenvolve um trabalho interno de sensibilização para as áreas que recebem servidores com PcD, na busca de proporcionar um ambiente inclusivo, através de mobilização, conscientização e reflexão quanto à realidade e às necessidades das pessoas com deficiência (TJPE, 2019a).

Brito e Maranhão (2020) reforçam que é necessário compreender as limitações da pessoa com deficiência e sugerem que as relações sociais sejam o primeiro ponto a ser trabalhado. Para Cavalcante (2020), para uma efetiva inclusão, as barreiras atitudinais devem ser trabalhadas, pelo desconhecimento da sociedade em relação ao tratamento com os diferentes. É necessário desenvolver a empatia e quebrar os preconceitos equivocados a esse grupo com o objetivo de desenvolver um clima organizacional que possibilite a confiança mútua e o compartilhamento de experiências e conhecimentos (Machado, 2019).

O Programa de Acessibilidade e Inclusão desenvolvido pela UAF encontra-se apresentado na Cartilha de Inclusão e Acessibilidade do Tribunal de Justiça, publicado no ano de 2019 (TJPE, 2019a, p. 30) e executa ações como:

- $\quad$ Sensibilização para a inclusão no ambiente de trabalho, interagindo com gestores e equipes, buscando um local de trabalho acessível e livre de barreiras, com a elaboração da cartilha de inclusão e acessibilidade;

- $\quad$ Acompanhamento de servidores com deficiência que apresentam dificuldades funcionais e de relacionamento no ambiente de trabalho;

- Pesquisa online sobre adaptação funcional e levantamento de demandas/ necessidade de tecnologia assistiva, e encaminhamento das demandas aos setores competentes;

- $\quad$ Promoção de oficinas de LIBRAS e de Braille em diversas comarcas do estado.

Porém, pelos dados apresentados em relatório publicado em abril de 2021 (TJPE, 2021) sobre o quantitativo de cargos efetivos e de magistrados, podemos observar que percentual de cargos do TJPE ainda está aquém do preconizado em legislação (Quadro 3), tendo ainda espaço para absorver em seu quadro funcional uma maior quantidade de pessoas com deficiência. Dos 7.282 cargos ocupados, retirando-se os 179 já conhecidamente ocupados por PcD, temos um percentual de 2,52\% de cargos destinados à essa força de trabalho. 
Quadro 3. Quantitativo de Cargos Efetivos e de Magistrados do PJPE.

\begin{tabular}{|c|c|}
\hline Cargo & Ocupados \\
\hline Analista APJ & 1.867 \\
\hline Oficial OPJ & 651 \\
\hline Técnico TPJ & 3628 \\
\hline Oficial PJ III & 409 \\
\hline Auxiliar PJ I & 183 \\
\hline Magistrados & 544 \\
\hline SOMA & 7.282 \\
\hline Cargos PcD & 179 \\
\hline Cargos não PcD & 7.103 \\
\hline Percentual & $2,52 \%$ \\
\hline
\end{tabular}

Fonte: Autores.

\subsection{A Comissão Permanente de Acessibilidade e Inclusão}

Seguindo a orientação do CNJ, através da Resolução no 230/2016 (CNJ, 2016), o TJPE instituiu pelo Ato nº 808/2016 (TJPE, 2016) sua primeira Comissão Permanente de Acessibilidade de Inclusão (CACIN), composta por representantes da alta gestão e 01 (um) servidor com deficiência, com o objetivo de fixar metas anuais direcionadas à promoção de inclusão e acessibilidade para pessoa com deficiência, dando as primeiras diretrizes sobre o assunto, dentre as quais: sensibilizar e preparar magistrados e servidores para atender pessoas com deficiência; esforçar-se pela remoção de barreiras e promover a acessibilidade; entre outras ações.

Revogando o Ato supracitado, o Ato no 164/2018 (TJPE, 2018), instituiu nova Comissão Permanente de Inclusão e Acessibilidade, vinculada à Presidência do TJPE, com o objetivo de promover a acessibilidade de forma ampla, tanto ao seu corpo funcional como aos cidadãos com deficiência ou mobilidade reduzida. Formada por uma equipe composta por 01 magistrado, equipe técnica multidisciplinar com representantes das áreas de recursos humanos, saúde, tecnologia, comunicação e engenharia da organização, e mais 04 (quatro) servidores com deficiência ou que tenham filhos com deficiência. $\mathrm{O}$ inciso $1^{\circ}$ do art. $3^{\circ}$ desse Ato sugere que os quatro representantes dos servidores com deficiência tenham diferentes tipos de deficiência para melhor representar as várias realidades.

No ano de 2019, foi publicada a Resolução n 424/2019 (TJPE, 2019b), revogando o Ato no 164/2018, imprimindo mais força e perenidade à comissão. As atas de reuniões do CACIN, bem como as ações desenvolvidas pela comissão, com o intuito de dar visibilidade aos encaminhamentos, encontram-se publicadas em área específica do site do TJPE (TJPE, 2021).

Desde a constituição da nova comissão em 2018, formada por equipe multidisciplinar com componentes de áreas administrativas do TJPE e servidores com diferentes deficiências, reuniões periódicas vêm tratando as demandas identificadas e buscando soluções para implementação no órgão. Diversas iniciativas já lograram êxito como verificação e melhoria da acessibilidade nos principais prédios dos TJPE, levantamento de necessidades e adequação de tecnologias assistivas, cursos de libras para servidores selecionados por localização estratégica, cursos de barreiras atitudinais buscando desmistificar as deficiências, dentre outras. Para aos servidores com deficiência o CACIN é atualmente a unidade que, junto com eles, defende e briga pelo direito à um trabalho acessível e inclusivo. 
Em relação ao levantamento das tecnologias assistivas, que oferecem possibilidade de aumento da produtividade por compensar deficiências (Mark et al., 2019), várias ações já foram implementadas como disponibilização de software leitor de tela, aquisição de lupas eletrônicas para aumento das telas de computador, aquisição de scanners com software capaz de transformar documento impresso scaneado em texto acessível por leitor de tela, porém ainda se faz necessário acompanhamento para verificar a eficácia do uso dessas ferramentas. Ressalta-se que, por serem equipamentos muito específicos, muitas vezes desconhecidas tanto pelos usuários quanto pelos profissionais (Rodrigues \& Coutinho, 2018), observa-se a necessidade de treinamentos para que toda a potencialidade seja aproveitada.

Outro fator complicador em relação à aquisição de tecnologia assistiva no serviço público é o fato de que somente se conhece a real necessidade do servidor, quando ele toma posse do cargo, pois a necessidades de cada PcD são particulares, individuais, e muitas vezes o equipamento que se adequa a uma pessoa não serve para outra. Também não se configura opção viável, a manutenção de estoque de equipamento pelo fato de exatamente não se ter como prever qual o tipo de deficiência do próximo nomeado que irá tomar posse no cargo, podendo um equipamento ser adquirido e nunca ser utilizado, tornando-se mal uso do recurso público.

Por isso as aquisições de tecnologia assistiva na organização são reativas, iniciando-se o processo de compra apenas após o início da atividade laboral do PcD, e ainda ficam a expostas à burocracia conhecida do processo de aquisição no serviço público. Hoje, a partir das solicitações individuais, já fazem parte do parque de TIC do TJPE scanners horizontais, teclados ergonômicos, software leitor de tela, impressora em Braille e outros, todos, de uso específico de cada servidor PcD solicitante do equipamento. Essa burocracia também foi percebida na pesquisa de Machado (2019).

Embora a UAF tente fazer todos os levantamentos iniciais possíveis, ocorre que o início da jornada laboral do servidor PcD recém nomeado, dependendo do grau da deficiência, torna-se um fator limitante e não inclusivo por não se apresentar uma estrutura de fácil montagem.

Em relação aos aplicativos e softwares utilizados pelos servidores do TJPE várias queixas ainda são conhecidas, principalmente pela quantidade de sistemas desenvolvidos em tempos passados, com pouca ou nenhuma preocupação com a acessibilidade. Com a estrutura organizacional bem formalizada e secular, o órgão possui vários pequenos sistemas que atendem as mais diversas áreas de negócio administrativas e judiciais.

Diante da necessidade de atualizar o site do TJPE, no segundo semestre de 2020, foi disponibilizada nova versão adequando-se as normativas de acessibilidade definida pelo Modelo de Acessibilidade do Governo Eletrônico - eMAG (BRASIL, 2014), porém alguns sistemas mais antigos, que são disponibilizados pela web, ainda estão sendo otimizados reativamente a partir de solicitações de usuários.

De maneira mais preocupante, ainda existem sistemas mais antigos, escritos em linguagens para sistemas locais, instalados em computadores, que também não foram construídos com o foco na acessibilidade e inclusão. A revisão desses sistemas não está hoje exposta nos planos formais da SETIC, com problemas de acessibilidade muitas vezes desconhecidos, demonstrando-se uma área de sombra para o atendimento ao PcD.

São pontos a serem observados pela acessibilidade e usabilidade dos sistemas, segundo o eMAG:

\footnotetext{
- Acesso ao computador sem mouse: no caso de pessoas com deficiência visual, dificuldade de controle dos movimentos, paralisia ou amputação de um membro superior;

- Acesso ao computador sem teclado: no caso de pessoas com amputações, grandes limitações de movimentos ou falta de força nos membros superiores;

- Acesso ao computador sem monitor: no caso de pessoas com cegueira;

- Acesso ao computador sem áudio: no caso de pessoas com deficiência auditiva.
} 
Observa-se ainda resistência quanto às implementações das ações, especialmente quando envolvem recursos financeiros. A falta de priorização das demandas do CACIN pelas unidades executoras emperra em burocracias internas e falta de responsabilização para as ações. A criação de uma unidade voltada para as demandas das PcD (CNJ, 2021) sugere maior compromisso, perenidade, sustentabilidade e foco no sentido da acessibilidade e inclusão.

\subsection{A adaptação do servidor com deficiência visual no TJPE}

Para o servidor com deficiência visual, o TJPE faz o acolhimento levantando as competências do profissional e as necessidades de tecnologia assistiva. Também é feito um trabalho junto à área que irá recebê-lo a fim de dirimir dúvidas e minimizar possíveis barreiras de quaisquer naturezas. A Unidade de Acompanhamento Funcional (UAF) é a unidade responsável por fazer a adaptação bem como o acompanhamento profissional do servidor PcD.

Segundo Trafford et al. (2021), o uso da uma tecnologia assistiva se propõe a melhorar vários aspectos da condição da pessoa com deficiência, oferecendo maior qualidade de vida e autonomia. A ausência de autonomia compromete o desenvolvimento e a autonomia no local de trabalho, prejudicando a produtividade da PcD (Figueiró, 2016). Na pesquisa de Barros e Ambiel (2020), foi mostrado que a falta de investimento em acessibilidade, incluindo recursos tecnológicos e equipamentos acessíveis se demonstrou um dos principais motivos de insatisfação no trabalho.

Nos casos de deficiência visual de grau leve, o TJPE hoje disponibiliza, quando solicitado, monitores de polegada superior ao padrão utilizado na organização e a lupa eletrônica para uso nas telas de computadores. Para os que possuem um grau elevado, podem ser instalado o software leitor de tela NVDA (NonVisual Desktop Access), que é gratuito e de código aberto, ou o leitor JAWS (Job Access With Speech) que tem as licenças limitadas dentro da organização por ter um alto custo. Outro recurso identificado foi scanners com os softwares Abbyy FineReader (licença paga) ou OpenBook (licença gratuita) que digitalizam documentos impressos fazendo reconhecimento óptico de caracteres (OCR), transformando a imagem em caracteres legíveis pelo leitor de tela (Schettini, 2020).

Em relação às aplicações, embora a organização defina que o e-mail institucional é ferramenta de comunicação oficial, as solicitações à unidade de gestão de pessoas sejam feitas por sistema eletrônico, os processos administrativos tramitem por meio eletrônico, sistemas que deveriam ser acessados por todos indistintamente, tanto das áreas administrativas como das áreas judiciais, a grande maioria deles, não foram testados em nenhuma das duas ferramentas para leitura de tela, não se garantindo o uso total das aplicações pelos servidores com deficiência visual.

Outro ponto dificultador é a inexistência de treinamento tanto no software leitor de tela, como nos sistemas específicos das unidades organizacionais utilizando leitor de tela. Quando o servidor com deficiência visual já ingressa na organização com o conhecimento no software leitor de tela, possui uma vantagem em relação ao que não tem o conhecimento, porém precisa aprender a utilizar os sistemas internos de maneira autônoma e intuitiva, configurando-se barreiras à inclusão, pois os treinamentos nos sistemas oferecidos pelo órgão não incluem o uso dos leitores.

Em pesquisa executada por Schettini (2019), especificamente sobre a acessibilidade do sistema de acompanhamento processual PJe (Processo Judicial Eletrônico), foi constatada a dificuldade de uso do sistema pelos servidores com deficiência visual, demonstrando na prática a necessidade de ações mais efetivas quanto à promoção da acessibilidade e inclusão nos sistemas informatizados do TJPE. É importante ressaltar que, o referido sistema atende ao maior público do TJPE, abrangendo servidores da área fim da organização, servidores de órgãos parceiros da justiça e público externo, como advogados e cidadãos em geral.

Embora a "lei de cotas" tenha sido publicada a mais de 25 anos, o processo de evolução das relações socioprofissionais e das práticas de uma gestão inclusiva ainda precisam de maiores esforços (Werneck-Souza et al., 2020). De 
acordo com Ramachandra et al. (2021), as organizações precisam adotar abordagens mais planejadas e proativas para inclusão laboral do PcD.

Para que a cultura de inclusão seja fortalecida e o potencial dos servidores com deficiência visual seja aproveitado é necessário compromisso da alta gestão, patrocinando a inclusão em todos os sentidos com vistas a incentivar o comportamento dos demais (Neves-Silva et al., 2015), bem como o desenvolvimento de programas para promover a cultura inclusiva envolvendo toda a organização (Hammes \& Nuernberg, 2015).

\section{Considerações Finais}

Acompanhando o processo histórico de inclusão das pessoas com deficiência no mercado de trabalho, motivado pela comunidade internacional e plenamente absorvido pelo Brasil através de sua legislação, o Tribunal de Justiça de Pernambuco desenvolve ações dentro da organização praticando a inclusão laboral.

Também motivadas pelo Conselho Nacional de Justiça, órgão que regula o judiciário nacional, as ações de inclusão dentro do TJPE se guiam pelas determinações e resoluções desse órgão, que são monitoradas anualmente e vem evoluindo a partir do amadurecimento do tema na sociedade.

Incluindo em seus concursos cota para a mão de obra de PcD, a partir do concurso de 2001, hoje o órgão efetua acolhimento e acompanhamento desses servidores nas unidades organizacionais, executa anualmente o levantamento de necessidades de tecnologia assistiva, dentre outras ações através da Unidade de Acompanhamento Funcional da Secretaria de Gestão de Pessoas. Com a criação da Comissão de Inclusão e Acessibilidade, mais efetivamente a partir de 2018, o tema vem ganhando espaço dentro do órgão, onde uma equipe multidisciplinar se encarrega, cada um em sua especialidade, de ouvir demandas e pensar soluções para a efetiva inclusão tanto para os servidores com deficiência como para todo o público externo. É importante ressaltar a participação de representantes de servidores com deficiência na Comissão para que as soluções sejam validadas.

Observa-se que o processo de inclusão no TJPE caminha em processo de evolução, mas que ainda se fazem necessários ajustes para adequação à própria legislação vigente quanto à cota recomendada e adequação do ambiente laboral.

Ainda existem barreiras de falta de conhecimento e muita burocracia para que ocorra maior dinamização para a adaptação da acessibilidade do local de trabalho para PcD no TJPE, especialmente, quando se trata de tecnologia assistiva.

Também em relação aos sistemas informatizados internos não se tem um processo desenhado de revisão de acessibilidade, bem como não se tem a cultura de incluir esse tema nas novas aplicações, ainda sendo um processo reativo quando questionado pelo próprio usuário com deficiência.

A indicação de criação de uma unidade organizacional responsável pelo olhar para a $\mathrm{PcD}$, em resolução publicada esse ano pelo $\mathrm{CNJ}$, tende a reforçar a preocupação com a efetividade e a sustentabilidade do processo de inclusão dentro dos órgãos do Poder Judiciário. Trata-se de um tema multidisciplinar, sendo necessário o desenvolvimento de uma cultura que se antecipe às necessidades, buscando junto com os servidores portadores de deficiência, as melhores soluções para uma inclusão justa e plena.

A literatura especializada é muito carente de trabalhos científicos que abordam a temática da PcD no âmbito do sistema judiciário brasileiro, especialmente, quando se refere à utilização da Tecnologia da Informação e Comunicação. Em decorrência de sua extrema importância social, o tema deve ser bastante aprofundado dentro da academia.

Sugerimos como trabalho futuro, a realização de pesquisa de opinião junto aos servidores com deficiências do TJPE, com a finalidade de se saber a realidade laboral desses trabalhadores na referida instituição. 


\section{Referências}

Andrade, F. S. \& Bublitz, M. D. (2016) Notas sobre o estatuto da pessoa com deficiência (lei 13.146/2015) e a alteração da curatela e do regime de capacidade. Revista Jurídica Cesumar, 16 (3), 707-727. http://dx.doi.org/ 10.17765/2176-9184.2016v16n3p707-727.

Barros, L. O. \& Ambiel, R. A. M. (2020). "Não tem nada para fazer lá": Trabalho e pessoas com deficiência visual. Psico, 51 (1), 1-12. http://dx.doi.org/10.15448/1980-8623.2020.1.31320.

Brasil. (1988). Constituição da República Federativa do Brasil de 1988. Presidência da República.

Brasil (1989). Lei $\mathrm{n}^{\circ}$ 7.853, de 24 d outubro de 1989. Dispõe sobre o apoio às pessoas portadoras de deficiência, sua integração social, sobre a Coordenadoria Nacional para Integração da Pessoa Portadora de Deficiência - Corde, institui a tutela jurisdicional de interesses coletivos ou difusos dessas pessoas, disciplina a atuação do Ministério Público, define crimes, e dá outras providências. Presidência da República. https://www.planalto.gov.br/ccivil_03/Leis/L7853.htm.

Brasil (1990). Lei $\mathrm{n}^{\circ}$ 8.112, de 11 de dezembro de 1990. Dispõe sobre o regime jurídico dos servidores públicos civis da União, das autarquias e das fundações públicas federais. Presidência da República. http://www.planalto.gov.br/ccivil_03/LEIS/L8112cons.htm.

Brasil (1991). Lei no 8.213, de 24 de julho de 1991. Dispõe sobre os Planos de Benefícios da Previdência Social e dá outras providências (Lei de Cotas). Presidência da República. https://www.planalto.gov.br/ccivil_03/leis/18213cons.htm.

Brasil (1997). Lei $\mathrm{n}^{\circ}$ 9.527, de 10 de dezembro de 1997. Altera dispositivos das Leis $n^{\circ}$ s 8.112, de 11 de dezembro de 1990, 8.460, de 17 de setembro de 1992, e 2.180, de 5 de fevereiro de 1954, e dá outras providências. Presidência da República. http://www.planalto.gov.br/ccivil_03/LEIS/ L9527.htm.

Brasil (2000). Lei $\mathrm{n}^{\circ}$ 10.098, de 19 de dezembro de 2000. Estabelece normas gerais e critérios básicos para a promoção da acessibilidade das pessoas portadoras de deficiência ou com mobilidade reduzida, e dá outras providências (Lei da Acessibilidade). Presidência da República. https://www.planalto.gov.br/ccivil_03/LEIS/ L10098.htm.

Brasil (2004). Decreto $\mathrm{n}^{\circ}$ 5.296, de 2 de dezembro de 2004. Regulamenta as Leis nos 10.048, de 8 de novembro de 2000, que dá prioridade de atendimento às pessoas que especifica, e 10.098, de 19 de dezembro de 2000, que estabelece normas gerais e critérios básicos para a promoção da acessibilidade das pessoas portadoras de deficiência ou com mobilidade reduzida, e dá outras providências. Presidência da República. https://www.planalto.gov.br/ccivil_03/_ato2004-2006/2004/decreto/d5296.htm.

Brasil (2009). Decreto $\mathrm{n}^{\circ}$ 6.949, de 25 de agosto de 2009. Promulga a Convenção Internacional sobre os Direitos das Pessoas com Deficiência e seu Protocolo Facultativo, assinados em Nova York, em 30 de março de 2007. Presidência da República. http://www.planalto.gov.br/ccivil_03/_ato20072010/2009/decreto/d6949.htm.

Brasil. (2014). E-Mag - Modelo de Acessibilidade em Governo Eletrônico. Presidência da República. http://emag.governoeletronico.gov.br.

Brasil (2015). Lei no 13.146, de 6 de julho de 2015. Institui a Lei Brasileira de Inclusão da Pessoa com Deficiência (Estatuto da Pessoa com Deficiência). Brasília, DF: Presidência da República. https://presrepublica.jusbrasil.com.br/legislacao/205855325/lei-13146-15.

Brasil (2018). Decreto $\mathrm{n}^{\circ}$ 9.508, de 24 de setembro de 2018. Reserva às pessoas com deficiência percentual de cargos e de empregos públicos ofertados em concursos públicos e em processos seletivos no âmbito da administração pública federal direta e indireta. Presidência da República. http://www.planalto.gov.br/ccivil_03/_Ato2015-2018/2018/Decreto/D9508.htm.

Brito, R. A. \& Maranhão, T. L. G. (2020). Os principais desafios das pessoas com deficiência em adentrar o mercado de trabalho: Revisão sistemática da literatura. Id on Line Revista Multidisciplinar e de Psicologia, 14 (51), 622-645. http://dx.doi.org/10.14295/idonline.v14i51.2623.

Cavalcante, L. G. S. (2020). A inclusão das pessoas com deficiência no meio ambiente de trabalho: A função social das empresas. Dissertação (Mestrado em Direitos e Garantias Fundamentais) - Faculdade de Direito de Vitória (FDV), Vitória. http://191.252.194.60:8080/handle/fdv/868.

CNJ (2009). Conselho Nacional de Justiça. Recomendação n. 27, de 16 de dezembro de 2009. In Guia de Normas Socioambientais do CNJ. Brasília: CNJ. 2012, 14-16. https://bibliotecadigital.cnj.jus.br/handle/123456789/293.

CNJ (2015). Resolução $\mathrm{n}^{\circ}$ 201, de 03 de março de 2015. Dispõe sobre a criação e competências das unidades ou núcleos socioambientais nos órgãos e conselhos do Poder Judiciário e implantação do respectivo Plano de Logística Sustentável (PLS-PJ). https://atos.cnj.jus.br/atos/detalhar/2126.

CNJ (2016). Resolução $\mathrm{n}^{\circ}$ 230, de 22 de junho de 2016. Orienta a adequação das atividades dos órgãos do Poder Judiciário e de seus serviços auxiliares às determinações exaradas pela Convenção Internacional sobre os Direitos das Pessoas com Deficiência e seu Protocolo Facultativo e pela Lei Brasileira de Inclusão da Pessoa com Deficiência por meio - entre outras medidas - da convolação em resolução a Recomendação CNJ 27, de 16/12/2009, bem como da instituição de Comissões Permanentes de Acessibilidade e Inclusão. https://atos.cnj.jus.br/atos/detalhar/2301.

CNJ (2020a). Conselho Nacional de Justiça. $4^{\text {o }}$ Balanço Socioambiental do Poder Judiciário. https://www.cnj.jus.br/wpcontent/uploads/2020/06/4balanco_socioambiental2020.pdf.

CNJ (2020b). Resolução no 343, de 09 de setembro de 2020. Institui condições especiais de trabalho para magistrados(as) e servidores(as) com deficiência, necessidades especiais ou doença grave ou que sejam pais ou responsáveis por dependentes nessa mesma condição e dá outras providências. https://atos.cnj.jus.br/atos/detalhar/3459.

CNJ (2021a). Conselho Nacional de Justiça. Quem somos. https://www.cnj.jus.br/sobre-o-cnj/quem-somos/.

CNJ (2021b). Resolução $\mathrm{n}^{\circ}$ 401, de 16 de junho de 2021. Dispõe sobre o desenvolvimento de diretrizes de acessibilidade e inclusão de pessoas com deficiência nos órgãos do Poder Judiciário e de seus serviços auxiliares, e regulamenta o funcionamento de unidades de acessibilidade e inclusão. https://atos.cnj.jus.br/atos/detalhar/3987. 
Figueiró, G. A. (2016). A dimensão comunicacional na inclusão de pessoas com deficiência em organizações. Trabalho de Conclusão de Curso (Graduação em Relações Públicas) - Universidade Federal do Rio Grande do Sul. https://www.lume.ufrgs.br/handle/10183/147097.

Galvão, M. C. B. \& Ricarte, I. L. M. (2020). Revisão sistemática da literatura: Conceituação, produção e publicação. Logeion: Filosofia da informação, 6 (1), 57-73. https://doi.org/10.21728/logeion. 2019v6n1.p57-73.

Hammes, I. C. \& Nuernberg, A. H. (2015). A inclusão de pessoas com deficiência no contexto do trabalho em Florianópolis: Relato de experiência no Sistema Nacional de Emprego. Psicologia: Ciência e profissão, 35(3), 768-780. http://dx.doi.org/10.1590/1982-3703000212012.

Lima, A. C. D., Cunha, D. A., Albuquerque, R. C., Costa, R. N. A. \& Silva, H. J. (2019). Alterações sensoriais em respiradores orais: revisão sistemática baseada no método Prisma. Revista Paulista de Pediatria, 37 (1). https://doi.org/10.1590/1984-0462/;2019;37;1; 00012.

Machado, J. L. (2019). Gestão Inclusiva: Propostas para a Inclusão Laboral em uma IFES. Dissertação (Mestrado em Engenharia de Produção) Universidade Federal do Rio Grande do Sul, https://www.lume.ufrgs.br/handle/10183/147097.

Maior, I. M. M. L. (2017). Movimento político das pessoas com deficiência reflexões sobre a conquista de direitos. Inclusão Social, 10 (2), 28-36. http://revista.ibict.br/inclusao/article/view/4029.

Mark, B. G., Hofmayer, S., Rauch, E. \& Matt, D. (2019). Inclusão de trabalhadores com deficiência na produção 4.0: Fundamentos jurídicos na Europa e potenciais por meio de sistemas de assistência ao trabalhador. Sustainability, 11 (21), 5978. https://doi.org/10.3390/su11215978.

Nascimento, H. J. (2019). A eficácia da aplicação do estatuto da pessoa com deficiência em empresas comerciais de Caruaru-PE. Monografia (Bacharel em Administração). Universidade Federal de Pernambuco, https://repositorio.ufpe.br/bitstream/123456789/37151/1/NASCIMENT O\%2C\%20Henrique\%20Jos\%C3\%A9\%20do.pdf.

Neves-Silva, P., Prais, F. G. \& Silveira, A. M. (2015). Inclusão da pessoa com deficiência no mercado de trabalho em Belo Horizonte, Brasil: Cenário e perspectiva. Ciência \& Saúde coletiva. 20 (8), 2549-2558. https://doi.org/10.1590/1413-81232015208.17802014.

Oliveira, M. [Márcia] S. (2017) A inserção de pessoas com deficiência no mercado de trabalho, no estado de Goiás. Dissertação (Mestrado em Desenvolvimento Regional) - Centro Universitário Alves Faria (UniAlfa), http://tede.unialfa.com. br/jspui/handle/tede/190.

Oliveira, M. [Milena] S. (2017). O direito ao trabalho por parte das pessoas com deficiência - o acesso ao cargo público e seu efetivo exercício. Dissertação (Mestrado em Direito Constitucional) - Universidade Federal do Ceará, Fortaleza. http://repositorio.ufc.br/bitstream/riufc/50561/1/2017_dis_msoliveira.pdf.

ONU (1948). Organização das Nações Unidas. Resolução no 217 A (III) da Assembleia Geral das Nações Unidas em 10 de dezembro de 1948. Declaração Universal dos Direitos Humanos. https://www.un.org/en/about-us/universal-declaration-of-human-rights.

ONU (1993). Organização das Nações Unidas. Resolução ONU 48/96, de 20 de dezembro de 1993. Regras Padrão sobre a Igualdade de Oportunidades para Pessoas com Deficiências. https://digitallibrary.un.org/record/179727.

Pernambuco. (1989). Constituição do Estado de Pernambuco. Recife, PE. http://www.alepe.pe.gov.br/wp-content/uploads/2015/05/constituicaoestadual.pdf.

Ramachandra, S. S., Murthy, G. V., Shamanna, B. R., Allagh, K. P., Pant, H. B. \& John, N. (2017). Fatores que influenciam o emprego e a empregabilidade de pessoas com deficiência: Insights de uma cidade no sul da Índia. Indian Journal Occupational \& Environmental Medicine, 21 (1), 36-41. https://www.ijoem.com/text.asp?2017/ 21/1/36/220695.

Rodrigues, G. F. \& Coutinho, K. S. (2018). Tecnologia assistiva para inclusão laboral: O que a internet tem a oferecer? Revista Observatório, 4 (3), 54-84. https://doi.org/10.20873/uft.2447-4266.2018v4n3p54.

Schettini, G. (2020) PJe-PE acessível: medidas práticas para a inclusão profissional. Dissertação (Mestrado em Inovação) - Centro Universitário dos Guararapes-UNIFG, Jaboatão dos Guararapes, 2020.

Trafford, Z., Van Der Westhuizen, E., Mcdonald, S., Linegar, M. \& Swartz, L. (2021). Mais do que apenas dispositivos de assistência: como uma empresa social sul-africana apoia um ambiente de inclusão. International Journal of Environmental Research and Public Health, 18 (5): 2655. https://doi.org/10.3390/ijerph18052655.

TJPE (2001). Tribunal de Justiça de Pernambuco. Edital $\mathrm{n}^{\circ}$ 01/2001 - TJPE, de 27 de abril de 2001. Concurso público para provimento de vagas nos cargos de nível superior, de nível médio, de nível intermediário e de nível fundamental. http://www.cespe.unb.br/concursos/_antigos/anteriores_2002/ 2001/tjpe2001/Arquivos/Ed_TJPE_2001_1.pdf.

TJPE (2007). Tribunal de Justiça de Pernambuco. Edital $\mathrm{n}^{\circ}$ 01/2007 - TJPE, de 16 de fevereiro de 2007. Concurso público de provas para provimento de cargos de técnico judiciário, analista judiciário e oficial de justiça. https://www.tjpe.jus.br/web/concursos-e-selecoes/concurso-servidor-2006.

TJPE (2010). Tribunal de Justiça de Pernambuco. Edital no 01/2010 de abertura de inscrições - TJPE, de 25 de novembro de 2010 . Concurso público para provimento de cargo de juiz substituto. https://www.tjpe.jus.br/web/concursos-e-selecoes/juiz-substituto-2010.

TJPE (2011). Tribunal de Justiça de Pernambuco. Edital $\mathrm{n}^{\circ}$ 01/2011 de abertura de inscrições - TJPE, de 03 de outubro de 2011 . Concurso público. https://www.tjpe.jus.br/web/concursos-e-selecoes/concurso-servidor-2011.

TJPE (2012). Tribunal de Justiça de Pernambuco. Edital no 01/2012 de abertura de inscrições - TJPE, de 19 de outubro de 2012 . Concurso público para provimento de cargo de juiz substituto. https://www.tjpe. jus.br/web/concursos-e-selecoes/juiz-substituto-2012.

TJPE (2014). Tribunal de Justiça de Pernambuco. Edital nº 01/2014 de abertura de inscrições - TJPE, de 19 de dezembro de 2014 . Concurso público para provimento de cargo de juiz substituto. http://www.concursosfcc.com.br/concursos/tjupe114/index.html.

TJPE (2016). Tribunal de Justiça de Pernambuco. Ato $\mathrm{n}^{\circ}$ 808, de 08 de agosto de 2016. Institui a Comissão Permanente de Acessibilidade e Inclusão. Diário da Justiça Eletrônico, Recife, PE, 09 de agosto de 2016. 
Research, Society and Development, v. 10, n. 9, e47810918371, 2021

(CC BY 4.0) | ISSN 2525-3409 | DOI: http://dx.doi.org/10.33448/rsd-v10i9.18371

TJPE (2017). Tribunal de Justiça de Pernambuco. Edital nº 01/2017 - TJPE, de 13 de julho de 2017. Concurso público. https://www.tjpe.jus.br/web/concursose-selecoes/concurso-servidor-2017.

TJPE (2018). Tribunal de Justiça de Pernambuco. Ato ${ }^{\circ} 164$, de 31 de janeiro de 2018. Revoga o ato $n^{\circ}$ 808/2016 que instituiu a Comissão Permanente de Acessibilidade e Inclusão no âmbito do Poder Judiciário do Estado de Pernambuco e dá outras providências. Diário da Justiça Eletrônico, Recife, PE, 01 de fevereiro de 2018 .

TJPE (2019a). Tribunal de Justiça de Pernambuco. Cartilha de Inclusão e Acessibilidade do Tribunal de Justiça de Pernambuco.

TJPE (2019b). Tribunal de Justiça de Pernambuco. Resolução $\mathrm{n}^{\circ}$ 424, de 02 de setembro de 2019. Instituiu a Comissão Permanente de Acessibilidade e Inclusão (CACIN) no âmbito do Poder Judiciário do Estado de Pernambuco. Diário da Justiça Eletrônico, Recife, PE, 04 de setembro de 2019.

TJPE (2021). Tribunal de Justiça de Pernambuco. Site da Transparência. https://www.tjpe.jus.br/web/ transparencia.

Verçosa, V. F. (2017). A inclusão da pessoa com deficiência através do meio ambiente do trabalho. Trabalho de Conclusão de Curso (Graduação em Direito) Universidade do Estado do Amazonas, http://repositorioinstitucional.uea.edu.br/handle/riuea/961.

Werneck-Souza, J., Ferreira, M. C. \& Soares, K. J. (2020). Panorama da produção brasileira sobre inserção de pessoas com deficiência no trabalho: Desafios à efetiva inclusão. Revista Interinstitucional de Psicologia, 13 (1). http://dx.doi.org/10.36298/gerais2020130104. 